\title{
An Artifact-Based Framework for Business-IT Misalignment Symptom Detection
}

\author{
Dóra Őri \\ Corvinus University of Budapest, Department of Information Systems, Budapest, Hungary \\ Doridinformatika.uni-corvinus.hu
}

\begin{abstract}
Enterprise architecture-based approaches give an in-depth analytic potential for alignment and misalignment assessment. The ability to incorporate these analytic potentials is an ongoing concern in the state-of-the-art strategic alignment literature. This paper proposes a framework for EA artifact-based misalignment symptom detection. The framework aims to perform a systematic, EA-based analysis of mismatches between the business and IT dimensions of the traditional Strategic Alignment Model (SAM). By operating the framework, containing EA-artifacts and suitable EA analysis types are connected to typical misalignment symptoms along the traditional alignment perspectives. The operation of the framework is illustrated with a case study about a fleet management project at a road management authority.
\end{abstract}

Keywords: Strategic Alignment Perspectives, Misalignment Symptoms, EA Artifacts, Enterprise Architecture Analysis.

\section{Introduction}

Business-IT alignment is regarded as one of the most important issues on information systems (IS) research, since information systems foster the successful execution of business strategies. While organizations are continually trying to achieve or sustain alignment, they are suffering from difficulties which encumber the achievement of alignment. These difficulties, inabilities and unpleasant circumstances lead us to the phenomenon of misalignment, which is referred to as the inverse state of strategic alignment. In this undesired state organizations fail to achieve or sustain alignment, i.e. information systems and information technology (IT) are not used consistently with the business strategy. In addition, strategies, structures, processes and technology considerations are not perfectly harmonized between business and IT domains in an organization. There are several traditional alignment studies on evaluating alignment performance. On the contrary, misalignment issues are insufficiently emphasized in the alignment literature. Since organizations operate in the state of misalignment most of the times, considerable attention should be paid to the concept of misalignment. Misalignment assessment techniques help to understand the nature and the constraints of alignment. Furthermore, after assessing the state of misalignment, more precise realignment initiatives can be recommended. Beside the low attention on misalignment issues, (mis)alignment literature suffers from another severe shortage. Existing 
misalignment assessment frameworks incorporate different concepts from related research areas (such as [6] and [20]). However, the innate ability of the enterprise architecture (EA) concept to support (mis)alignment analysis is also insufficiently addressed in the literature (for exceptions see e.g. [7], [16] and [19]).

The aim of the paper is to contribute to the above mentioned concerns by introducing a framework that addresses these issues. The proposed framework performs misalignment analysis by taking a symptom-based approach. It uses an EAbased technique to detect the typical symptoms of misalignment in an organization. The framework builds on the traditional SAM model, in particular on the concept of alignment perspectives [12]. Misalignment symptoms are connected to the four traditional alignment perspectives (Strategy Execution, Technology Transformation, Competitive Potential and Service Level). The framework identifies typical misalignment symptoms within the traditional alignment perspectives. Relevant EA artifacts and EA analysis types are recommended to every detected symptom along the perspectives. The justification of recommended artifacts and EA analysis types lies in the following: EA artifacts may contain the misalignment symptom in question, while EA analysis types are - by functionality - able to detect the symptom in the artifacts. The contribution of the paper is that it connects typical misalignment symptoms with relevant EA artifacts and suitable EA analysis types along the traditional alignment perspectives.

The rest of the paper is organized as follows: Section 2 summarizes the theoretical context. Section 3 presents the proposed framework by introducing its construction and its constituent parts. Section 4 shows the operation of the framework. Section 5 discusses a case study including EA model structure and some symptom detection results. Section 6 introduces related work regarding EA-based (mis)alignment assessment. At the end of the paper conclusions are drawn and future research directions are determined.

\section{Theoretical Foundation}

The theoretical foundation of the paper is based on three parts. The first subsection deals with the concept of strategic alignment, especially the role of alignment perspectives. It is followed by a succinct introduction on misalignment assessment. Subsequently, the concept of enterprise architecture artifacts is deduced from EA basics.

Strategic Alignment Perspectives. Strategic alignment is an ideal organizational state/position in which IT is used consistently with the business strategy. Alignment models or approaches prescriptively define the method of achieving and sustaining alignment. There are several influential and well-recognized alignment models, such as the MIT model [18], the Baets model [2] or Henderson and Venkatraman's Strategic Alignment Model (SAM) [12]. The SAM model has four key domains of strategic choice (a.k.a. alignment domains): 1) Business Strategy, 2) Business Structure, 3) IT Strategy and 4) IT Structure [12]. There are four dominant alignment perspectives in the SAM: 1) Strategy Execution perspective highlights the supporting 
role of IT in business strategy-based business structure. 2) Technology Transformation perspective deals with the business value of IT. 3) Competitive Potential perspective emphasizes emerging information technologies which are able to provide competitive potential to the business. 4) Service Level perspective indicates different ways to IT-based business service improvement. Alignment perspectives cover 3 alignment domains in order to define directions for alignment domain analysis. Every alignment perspective consists of 2 alignment domain matches, a.k.a. perspective components. The SAM model detailed only four perspectives out of the 8 possible alignment perspectives. Additional perspectives are analysed by [10].

Misalignment Assessment. The common way of evaluating the state of business-IT alignment is alignment evaluation, which analyses the presence of this phenomenon. In case of analysing its absence or deficiencies, misalignment assessment is conducted. The need for misalignment assessment has already been mentioned in the high-profile literature review on business-IT alignment, presented by [8]. Misalignment is an undesired state in which organizations fail to achieve or sustain alignment. The set of detection, correction and prevention is the general process of handling misalignment [6]. There are different ways of categorizing misalignment assessment methods [6], e.g. the sign-based, the syndrome-based or the symptombased approach. Misalignment symptoms are regarded as inefficiencies, difficulties or inabilities which encumber alignment achievement. The identification (detection) of these symptoms indicates the state of misalignment in an organization. [6], [16] and [19] introduce misalignment symptom collections, showing typical mismatches in the operation of an organization. Misalignment symptoms can be classified via misfit categorizations. The categorization of Strong and Volkoff [20] builds on the misfit types of 1) Functionality, 2) Data, 3) Usability, 4) Role, 5) Control and 6) Organizational Culture.

Enterprise Architecture Artifacts. An architecture defines the fundamental structure of a system, including its components and their relationships [21]. Enterprise architecture is the fundamental setup of an enterprise, described by its components and their relationships [21]. An EA framework is a collection of descriptions and methods to create and manage EA. There are several influential EA frameworks, such as the Zachman Framework [25], the TOGAF framework [21] or the DODAF framework [11]. TOGAF (The Open Group Architecture Framework) is a holistic EA framework. It describes a metamodel for EA and proposes methods for building and maintaining enterprise architectures. Architecture domains are considered as different conceptualizations of an enterprise. TOGAF provides 4 architecture domains: 1) Business Architecture, 2) Data Architecture, 3) Application Architecture and 4) Technology Architecture. The core of the TOGAF approach is the Architecture Development Method (ADM), which proposes an iterative method for developing and managing enterprise architecture. It consists of 10 phases. Phase B-D cover the four architecture domains. TOGAF provides a minimum set of necessary EA models, called artifacts. These artifacts are attached to certain ADM phases. Enterprise architecture analysis types are methods that are capable of assessing EA models, e.g. evaluating dependencies, isolated objects, complexity, or heterogeneity. 


\section{Towards an Artifact-Based Misalignment Detection Framework}

This section provides an overview on the components and the construction of the proposed framework. The framework described in the subsequent parts of this section is a well-structured, easy-to-use tool to support misalignment symptom detection. The structure of the framework is based on 5 parts:

1) To provide a systematic way of constructing the framework, an adaptation of Noran's Meta-methodology [15] was used.

2) Alignment perspectives are used to structure the approach of misalignment symptom detection. Alignment perspectives are decomposed into the constituent SAM domain matches.

3-5) Misalignment symptom catalogue, artifact catalogue and EA analysis catalogue describe the potential elements of the misalignment detection framework.

The proposed framework uses an alignment perspective-driven approach. In the first step traditional alignment perspectives are provided with typical misalignment symptoms. In the second step relevant artifacts are connected to the misalignment symptoms, which may contain the symptom in question. In the third step suitable EA analysis types are recommended to the misalignment symptoms. These EA analysis types are able to detect the symptoms in the recommended containing artifacts. Figure 1 introduces the constituent parts and the structure of the proposed framework. In the next subsections the construction of the framework will be described. The operation of the framework will be introduced in Section 4.

To support the construction as well as the coherence of the proposed framework, Meta-methodology concept [15], an EA-based supportive method was used. Metamethodology provides a systematic method to set up research frameworks. The concept builds on transformation logic, i.e. to produce new knowledge from input knowledge by means of operating the constructed research framework. The methodology was used to connect research concepts, related models and empirical data collections (misalignment symptom catalogues, artifact catalogues, EA analysis catalogues) in the proposed framework.

Traditional alignment perspectives were used to structure the approach of misalignment symptom detection. In the first step alignment perspectives were decomposed into the corresponding SAM domain matches. Table 1 introduces the constituent parts (the necessary SAM domain matches) of each traditional alignment perspective. To ease further reference, alignment perspectives and perspective components are coded. 


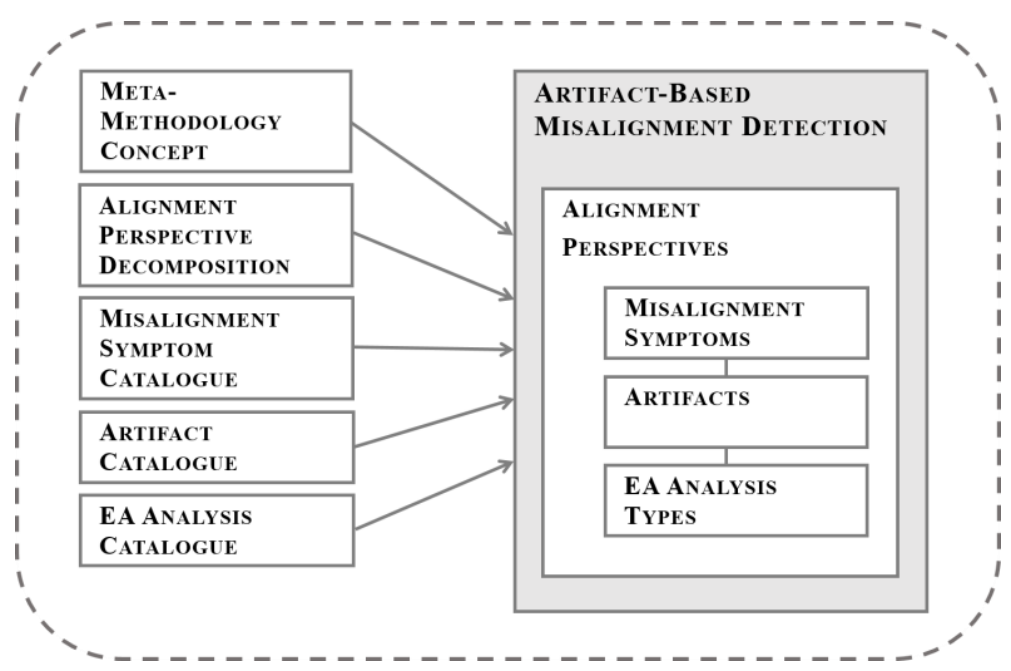

Fig. 1. The construction of Artifact-Based Misalignment Detection Framework

Table 1. Decomposition of alignment perspectives (based on [12])

\begin{tabular}{|l|c|c|c|c|}
\hline \multicolumn{1}{|c|}{ AlignMenT PERSPECTIVE } & $\begin{array}{l}\text { P.01 } \\
\text { Strategy } \\
\text { Execution }\end{array}$ & $\begin{array}{l}\text { P.02 } \\
\text { Technology } \\
\text { Transformation }\end{array}$ & $\begin{array}{l}\text { P.03 } \\
\text { Competitive } \\
\text { Potential }\end{array}$ & $\begin{array}{l}\text { P.04 } \\
\text { Service } \\
\text { Level }\end{array}$ \\
\hline $\begin{array}{l}\text { C.01 Matching of Business Strategy } \\
\text { and Business Structure domains }\end{array}$ & $\bullet$ & & $\bullet$ & \\
\hline $\begin{array}{l}\text { C.02 Matching of Business Structure } \\
\text { and IT Structure domains }\end{array}$ & $\bullet$ & & & $\bullet$ \\
\hline $\begin{array}{l}\text { C.03 Matching of Business Strategy } \\
\text { and IT Strategy domains }\end{array}$ & & $\bullet$ & $\bullet$ & \\
\hline $\begin{array}{l}\text { C.04 Matching of IT Strategy and IT } \\
\text { Structure domains }\end{array}$ & & $\bullet$ & & $\bullet$ \\
\hline
\end{tabular}

Alignment domain matches may contain the signs of misalignment. In this approach the state of misalignment were identified by its symptoms. This framework uses specific symptoms to be detected along the alignment perspectives. The misalignment symptom catalogue (Table 2) is a collection of smaller symptom lists found in previous literature on misalignment [6], [16] and [19]. The table shows misalignment symptoms that will be used in the proposed framework. To ease further reference, misalignment symptoms are coded.

The next component of the proposed framework is the collection of possible EA artifacts. TOGAF-based artifacts are able to contain certain misalignment symptoms. In Table 3 possible artifacts are introduced. These artifacts were used in the proposed framework. The content of the artifact catalogue derives from the TOGAF standard [21]. It is an excerpt from the whole TOGAF artifact list. To ease further reference, artifacts are coded. 
Table 2. Misalignment symptom catalogue (based on [6], [16] and [19])

\begin{tabular}{|l|l|}
\hline COD E & MIS A LI G N M E N T S Y M P T O M \\
\hline S.01 & Undefined organizational mission, strategy and goals \\
\hline S.02 & Undefined business process goals, business process owners \\
\hline S.03 & Lack of relation between process goals and organizational goals \\
\hline$S .04$ & Undefined business roles or responsibilities \\
\hline$S .05$ & Undefined or multiple hierarchy or lines of reporting \\
\hline$S .06$ & Application functionality does not support at least one business process task \\
\hline$S .07$ & Business process task supported by more than one application \\
\hline$S .08$ & Critical business process does not depend on scalable and available applications \\
\hline$S .09$ & Inappropriate application functionality \\
\hline$S .10$ & Insufficient IT resources \\
\hline$S .11$ & Lack of IT skills and competencies \\
\hline$S .12$ & Lack of skills to develop or innovate certain types of products \\
\hline$S .13$ & Poor IT planning and portfolio management \\
\hline$S .14$ & Under capacity infrastructure \\
\hline$S .15$ & Lack or poor systems performance monitoring \\
\hline$S .16$ & Out of date technological infrastructure \\
\hline$S .17$ & Technological heterogeneity \\
\hline$S .18$ & Incompatible platforms or technologies \\
\hline$S .19$ & Frequent periods while applications are unavailable \\
\hline$S .20$ & Information consistency or integrity problems \\
\hline$S .21$ & Undefined business service levels \\
\hline
\end{tabular}

Table 3. Artifact catalogue (based on [21])

\begin{tabular}{|c|c|c|c|}
\hline CODE & ARTIFACT & BRIEF CONTENT & $\begin{array}{l}\text { TOGAF } \\
\text { ADM } \\
\text { PHASE }\end{array}$ \\
\hline$A F .01$ & $\begin{array}{l}\text { Driver/Goal/Objective } \\
\text { Catalogue }\end{array}$ & $\begin{array}{l}\text { A breakdown of drivers, goals, and objectives } \\
\text { to provide a cross-organizational reference of } \\
\text { driver fulfilment. }\end{array}$ & Phase B \\
\hline$A F .02$ & Role Catalogue & $\begin{array}{l}\text { A list of all authorization levels of an } \\
\text { organization. }\end{array}$ & Phase B \\
\hline$A F .03$ & $\begin{array}{l}\text { Business Service/Function } \\
\text { Catalogue }\end{array}$ & $\begin{array}{l}\text { A functional decomposition to identify } \\
\text { capabilities of an organization. }\end{array}$ & Phase B \\
\hline AF.04 & Contract/Measure Catalogue & $\begin{array}{l}\text { The master list of all agreed service contracts } \\
\text { (and contract measures) within an } \\
\text { organization. }\end{array}$ & Phase B \\
\hline AF.05 & Actor/Role Matrix & $\begin{array}{l}\text { A matrix to show which actors perform } \\
\text { which roles. }\end{array}$ & Phase B \\
\hline$A F .06$ & Business Footprint Diagram & $\begin{array}{l}\text { A mapping of business goals, organizational } \\
\text { units, business functions, business services, } \\
\text { and delivering technical components. }\end{array}$ & Phase B \\
\hline$A F .07$ & $\begin{array}{l}\text { Functional Decomposition } \\
\text { Diagram }\end{array}$ & $\begin{array}{l}\text { A list of relevant capabilities within an } \\
\text { organization. }\end{array}$ & Phase B \\
\hline AF.08 & $\begin{array}{l}\text { Goal/Objective/Service } \\
\text { Diagram }\end{array}$ & $\begin{array}{l}\text { A mapping to show how a service contributes } \\
\text { to the achievement of a business strategy. }\end{array}$ & Phase B \\
\hline AF.09 & Business Use-Case Diagram & $\begin{array}{l}\text { A diagram to show the relationships between } \\
\text { consumers and providers of business } \\
\text { services. }\end{array}$ & Phase B \\
\hline AF.10 & $\begin{array}{l}\text { Organizational Decomposition } \\
\text { Diagram }\end{array}$ & $\begin{array}{l}\text { A list of links between actors, roles, and } \\
\text { locations within an organization tree. }\end{array}$ & Phase B \\
\hline$A F .11$ & Process Flow Diagram & $\begin{array}{l}\text { A model to show sequential flow of tasks } \\
\text { within a business process. }\end{array}$ & Phase B \\
\hline
\end{tabular}




\begin{tabular}{|c|c|c|c|}
\hline$A F .12$ & $\begin{array}{l}\text { Data Entity/Data Component } \\
\text { Catalogue }\end{array}$ & $\begin{array}{l}\text { A list of all the data used across the } \\
\text { enterprise, incl. data entities \& components. }\end{array}$ & Phase C \\
\hline$A F .13$ & $\begin{array}{l}\text { Data Entity/Business Function } \\
\text { Matrix }\end{array}$ & $\begin{array}{l}\text { A list that links data entities and business } \\
\text { functions within an organization. }\end{array}$ & Phase C \\
\hline$A F .14$ & Data Migration Diagram & $\begin{array}{l}\text { A diagram that displays the flow of data from } \\
\text { the source to the target applications. }\end{array}$ & Phase C \\
\hline$A F .15$ & $\begin{array}{l}\text { Application Portfolio } \\
\text { Catalogue }\end{array}$ & $\begin{array}{l}\text { A catalogue to identify and maintain all the } \\
\text { applications in the organization. }\end{array}$ & Phase C \\
\hline$A F .16$ & Application/Function Matrix & $\begin{array}{l}\text { It links applications and business functions } \\
\text { within an organization. }\end{array}$ & Phase C \\
\hline$A F .17$ & Application Interaction Matrix & $\begin{array}{l}\text { A mapping that describes communications } \\
\text { relationships between applications. }\end{array}$ & Phase C \\
\hline AF.18 & $\begin{array}{l}\text { Application and User Location } \\
\text { Diagram }\end{array}$ & $\begin{array}{l}\text { A diagram to show the geographical } \\
\text { distribution of applications. }\end{array}$ & Phase C \\
\hline AF.19 & Application Use-Case Diagram & $\begin{array}{l}\text { A diagram to link consumers and providers of } \\
\text { application services. }\end{array}$ & Phase C \\
\hline AF.20 & $\begin{array}{l}\text { Process/Application } \\
\text { Realization Diagram }\end{array}$ & $\begin{array}{l}\text { A diagram to depict the sequence of events } \\
\text { when multiple applications are involved in } \\
\text { executing a business process. }\end{array}$ & Phase C \\
\hline$A F .21$ & Software Distribution Diagram & $\begin{array}{l}\text { A diagram to show how physical applications } \\
\text { are distributed across physical technology } \\
\text { and the location of that technology. }\end{array}$ & Phase C \\
\hline$A F .22$ & $\begin{array}{l}\text { Technology Portfolio } \\
\text { Catalogue }\end{array}$ & $\begin{array}{l}\text { A catalogue to identify and maintain all the } \\
\text { technology across the organization. }\end{array}$ & Phase D \\
\hline$A F .23$ & $\begin{array}{l}\text { Application/Technology } \\
\text { Matrix }\end{array}$ & $\begin{array}{l}\text { A mapping of applications to technology } \\
\text { platform. }\end{array}$ & Phase D \\
\hline$A F .24$ & $\begin{array}{l}\text { Platform Decomposition } \\
\text { Diagram }\end{array}$ & $\begin{array}{l}\text { A diagram to cover all aspects of the } \\
\text { infrastructure and technology platform. }\end{array}$ & Phase D \\
\hline$A F .25$ & Processing Diagram & $\begin{array}{l}\text { A diagram to show deployable units of code/ } \\
\text { configuration and how these are deployed } \\
\text { onto the technology platform. }\end{array}$ & Phase D \\
\hline
\end{tabular}

The final component of the proposed framework is the catalogue of suitable EA analysis types. EA analysis types are capable of revealing misalignment symptoms in the artifacts. In this framework 8 possible EA analysis types were used as recommended EA analysis types (Table 4). The content of the catalogue was collected from related literature on EA analysis [3], [14] and [23]. To ease further reference, EA analysis types are coded.

Table 4. EA analysis catalogue (based on [3], [14] and [23])

\begin{tabular}{|l|l|l|}
\hline COD E & EA ANALYS I S T Y P E & B RIE F CON TEN T \\
\hline$A .01$ & Dependency analysis & $\begin{array}{l}\text { Analysis of directly or indirectly linked EA entities, } \\
\text { relationship analysis and impact analysis. }\end{array}$ \\
\hline$A .02$ & Network analysis & Analysis of EA domain network and elements. \\
\hline$A .03$ & Coverage analysis & $\begin{array}{l}\text { Analysis of business structure coverage (by supportive } \\
\text { application systems). }\end{array}$ \\
\hline$A .04$ & Interface analysis & Analysis of interfaces between application systems. \\
\hline$A .05$ & Complexity analysis & $\begin{array}{l}\text { Analysis of architecture complexity by architecture } \\
\text { components and relationships. }\end{array}$ \\
\hline$A .06$ & $\begin{array}{l}\text { Enterprise interoperability } \\
\text { assessment }\end{array}$ & $\begin{array}{l}\text { Analysis of interoperability between architecture } \\
\text { entities and architecture domains. }\end{array}$ \\
\hline$A .07$ & Enterprise coherence assessment & Analysis of coherence between architecture entities. \\
\hline$A .08$ & Heterogeneity analysis & Analysis of IT assets heterogeneity. \\
\hline
\end{tabular}




\section{Operation of the Framework}

Section 4 introduces the operation of the proposed framework. It is built on the above introduced framework components. Four traditional alignment perspectives (P.01 Strategy Execution, P.02 Technology Transformation, P.03 Competitive Potential and P.04 Service Level) are analysed according to the approach of the framework. The main steps are presented in Figure 2.

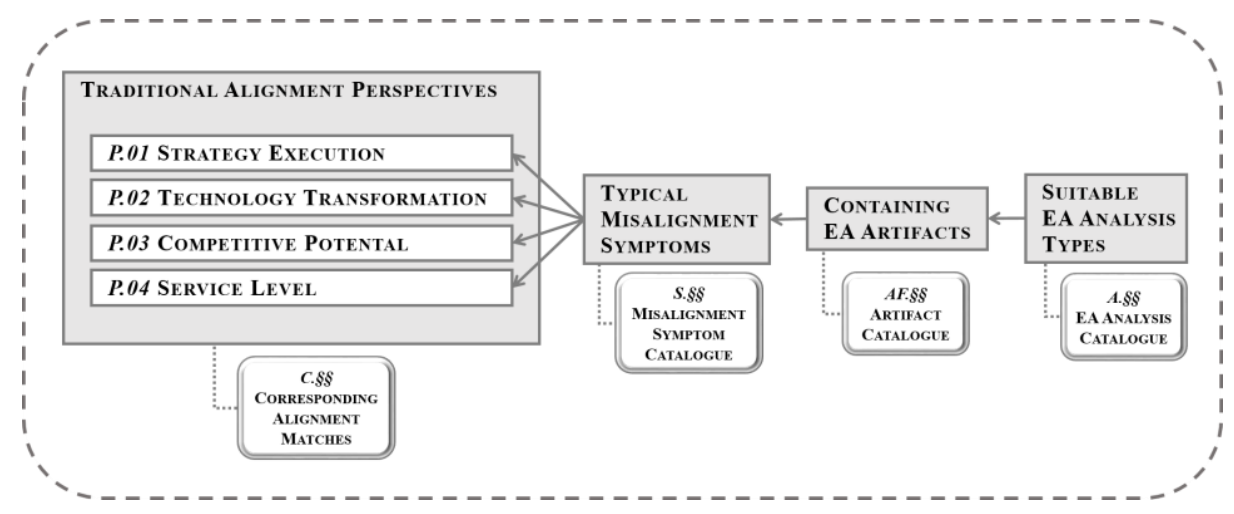

Fig. 2. The operation of Artifact-Based Misalignment Detection Framework

Traditional alignment perspectives are analysed according to the following steps: Firstly, alignment perspectives are decomposed into corresponding perspective components, a.k.a. alignment matches (C. $\S)$. Secondly, the most typical misalignment symptoms are connected to the perspective components - using the misalignment symptom catalogue $(\mathrm{S} . \S \S)$ as reference. Thirdly, relevant containing artifacts are attached to the misalignment symptoms in question. The artifact catalogue (AF. $\S)$ is used as reference. Finally, suitable EA analysis types are collected to the containing artifacts, using the EA analysis catalogue (A. $\S)$ as reference. Results of this matching are presented in the following structure:

- Results of Strategy Execution perspective are shown in Table 5. Investigated perspective components include: C.01 and C.02.

- Results of Technology Transformation perspective are introduced in Table 6. C.03 and C.04 perspective components were analysed in this part.

- Results of Competitive Potential perspective are displayed in Table 7. Inspected perspective components include: C.01 and C.03.

- Results of Service Level perspective are collected in Table 8. This perspective was analysed by C.02 and C.04 perspective components.

The results of this matching are presented in the following parts of the section. This contribution is part of an ongoing research. In this paper an excerpt is given from these matching results. In this digest the most typical misalignment symptoms are identified and analysed along the four traditional alignment perspectives. 
Table 5. Results of Strategy Execution perspective (P.01)

\begin{tabular}{|c|c|c|c|}
\hline $\begin{array}{l}\text { PERSPECTIVE } \\
\text { COMPONENT }\end{array}$ & $\begin{array}{l}\text { MISALIGNMENT } \\
\text { SYMPTOM }\end{array}$ & ARTIFACT & EA Analysis \\
\hline \multirow{2}{*}{$\begin{array}{l}\text { C.01 Matching of } \\
\text { Business Strategy } \\
\text { and Business } \\
\text { Structure domains }\end{array}$} & $\begin{array}{l}\text { S.01 Undefined } \\
\text { organizational } \\
\text { mission, strategy and } \\
\text { goals }\end{array}$ & $\begin{array}{l}\text { AF.01 Driver/Goal/ } \\
\text { Objective Catalogue } \\
\text { AF.06 Business Footprint } \\
\text { Diagram }\end{array}$ & A.03 Coverage analysis \\
\hline & $\begin{array}{l}\text { S.03 Lack of relation } \\
\text { between process } \\
\text { goals and } \\
\text { organizational goals }\end{array}$ & $\begin{array}{l}\text { AF.06 Business Footprint } \\
\text { Diagram } \\
\text { AF.08 Goal/Objective/ } \\
\text { Service Diagram }\end{array}$ & A.01 Dependency analysis \\
\hline \multirow{3}{*}{$\begin{array}{l}\text { C.02 Matching of } \\
\text { Business Structure } \\
\text { and IT Structure } \\
\text { domains }\end{array}$} & $\begin{array}{l}\text { S.06 Application } \\
\text { functionality does } \\
\text { not support at least } \\
\text { one business process } \\
\text { task }\end{array}$ & $\begin{array}{l}\text { AF.15 Application } \\
\text { Portfolio Catalogue } \\
\text { AF.16 Application/ } \\
\text { Function Matrix }\end{array}$ & A.01 Dependency analysis \\
\hline & $\begin{array}{l}\text { S.07 Business } \\
\text { process task } \\
\text { supported by more } \\
\text { than one application }\end{array}$ & $\begin{array}{l}\text { AF.15 Application } \\
\text { Portfolio Catalogue } \\
\text { AF.16 Application/ } \\
\text { Function Matrix }\end{array}$ & A.01 Dependency analysis \\
\hline & $\begin{array}{l}\text { S.09 Inappropriate } \\
\text { application } \\
\text { functionality }\end{array}$ & $\begin{array}{l}\text { AF.19 Application Use- } \\
\text { Case Diagram } \\
\text { AF.20 Process/Application } \\
\text { Realization Diagram }\end{array}$ & A.03 Coverage analysis \\
\hline
\end{tabular}

Table 6. Results of Technology Transformation perspective (P.02)

\begin{tabular}{|c|c|c|c|}
\hline $\begin{array}{l}\text { PERSPECTIVE } \\
\text { COMPONENT }\end{array}$ & $\begin{array}{l}\text { MISALIGNMENT } \\
\text { SYMPTOM }\end{array}$ & ARTIFACT & EA Analysis \\
\hline \multirow{2}{*}{$\begin{array}{l}\text { C.03 Matching of } \\
\text { Business Strategy } \\
\text { and IT Strategy } \\
\text { domains }\end{array}$} & $\begin{array}{l}\text { S.11 Lack of IT } \\
\text { skills and } \\
\text { competencies }\end{array}$ & $\begin{array}{l}\text { AF.02 Role Catalogue } \\
\text { AF.10 Organizational } \\
\text { Decomposition Diagram }\end{array}$ & A.03 Coverage analysis \\
\hline & $\begin{array}{l}\text { S.13 Poor IT } \\
\text { planning and } \\
\text { portfolio } \\
\text { management }\end{array}$ & $\begin{array}{l}\text { AF.07 Functional } \\
\text { Decomposition Diagram } \\
\text { AF.15 Application } \\
\text { Portfolio Catalogue }\end{array}$ & A.03 Coverage analysis \\
\hline \multirow{2}{*}{$\begin{array}{l}\text { C.04 Matching of } \\
\text { IT Strategy and IT } \\
\text { Structure domains }\end{array}$} & $\begin{array}{l}\text { S.10 Insufficient IT } \\
\text { resources }\end{array}$ & $\begin{array}{l}\text { AF.21 Software } \\
\text { Distribution Diagram } \\
\text { AF.24 Platform } \\
\text { Decomposition Diagram }\end{array}$ & A.05 Complexity analysis \\
\hline & $\begin{array}{l}\text { S.15 Lack or poor } \\
\text { systems performance } \\
\text { monitoring }\end{array}$ & AF.25 Processing Diagram & $\begin{array}{l}\text { A.07 Enterprise coherence } \\
\text { assessment }\end{array}$ \\
\hline
\end{tabular}


Table 7. Results of Competitive Potential perspective (P.03)

\begin{tabular}{|c|c|c|c|}
\hline $\begin{array}{l}\text { PERSPECTIVE } \\
\text { COMPONENT }\end{array}$ & $\begin{array}{l}\text { MISALIGNMENT } \\
\text { SYMPTOM }\end{array}$ & ARTIFACT & EA ANALYSIS \\
\hline \multirow{3}{*}{$\begin{array}{l}\text { C. } 03 \text { Matching of } \\
\text { Business Strategy } \\
\text { and IT Strategy } \\
\text { domains }\end{array}$} & $\begin{array}{l}\text { S.11 Lack of IT } \\
\text { skills and } \\
\text { competencies }\end{array}$ & AF.02 Role Catalogue & A. 03 Coverage analysis \\
\hline & $\begin{array}{l}\text { S.12 Lack of skills to } \\
\text { develop or innovate } \\
\text { certain types of } \\
\text { products }\end{array}$ & $\begin{array}{l}\text { AF.03 Business Service/ } \\
\text { Function Catalogue } \\
\text { AF.07 Functional } \\
\text { Decomposition Diagram }\end{array}$ & A. 03 Coverage analysis \\
\hline & $\begin{array}{l}\text { S.13 Poor IT } \\
\text { planning and } \\
\text { portfolio } \\
\text { management }\end{array}$ & $\begin{array}{l}\text { AF.07 Functional } \\
\text { Decomposition Diagram } \\
\text { AF.15 Application } \\
\text { Portfolio Catalogue }\end{array}$ & A. 03 Coverage analysis \\
\hline \multirow{2}{*}{$\begin{array}{l}\text { C.01 Matching of } \\
\text { Business Strategy } \\
\text { and Business } \\
\text { Structure domains }\end{array}$} & $\begin{array}{l}\text { S.03 Lack of relation } \\
\text { between process } \\
\text { goals and } \\
\text { organizational goals }\end{array}$ & $\begin{array}{l}\text { AF.06 Business Footprint } \\
\text { Diagram } \\
\text { AF.08 Goal/Objective/ } \\
\text { Service Diagram }\end{array}$ & A.01 Dependency analysis \\
\hline & $\begin{array}{l}\text { S.05 Undefined or } \\
\text { multiple hierarchy or } \\
\text { lines of reporting }\end{array}$ & $\begin{array}{l}\text { AF.02 Role Catalogue } \\
\text { AF.09 Business Use-Case } \\
\text { Diagram } \\
\text { AF.10 Organisational } \\
\text { Decomposition Diagram }\end{array}$ & $\begin{array}{l}\text { A.06 Enterprise } \\
\text { interoperability assessment }\end{array}$ \\
\hline
\end{tabular}

Table 8. Results of Service Level perspective (P.04)

\begin{tabular}{|c|c|c|c|}
\hline $\begin{array}{l}\text { PERSPECTIVE } \\
\text { COMPONENT }\end{array}$ & $\begin{array}{l}\text { MISALIGNMENT } \\
\text { SYMPTOM }\end{array}$ & ARTIFACT & EA ANALYSIS \\
\hline \multirow[t]{2}{*}{$\begin{array}{l}\text { C.04 Matching of } \\
\text { IT Strategy and IT } \\
\text { Structure domains }\end{array}$} & $\begin{array}{l}\text { S.17 Technological } \\
\text { heterogeneity }\end{array}$ & $\begin{array}{l}\text { AF.22 Technology } \\
\text { Portfolio Catalogue } \\
\text { AF.23 Application/ } \\
\text { Technology Matrix } \\
\text { AF.24 Platform } \\
\text { Decomposition Diagram }\end{array}$ & $\begin{array}{l}\text { A.08 Heterogeneity } \\
\text { analysis }\end{array}$ \\
\hline & $\begin{array}{l}\text { S.14 Under capacity } \\
\text { infrastructure }\end{array}$ & $\begin{array}{l}\text { AF.24 Platform } \\
\text { Decomposition Diagram }\end{array}$ & A.02 Network analysis \\
\hline \multirow{3}{*}{$\begin{array}{l}\text { C. } 02 \text { Matching of } \\
\text { Business Structure } \\
\text { and IT Structure } \\
\text { domains }\end{array}$} & $\begin{array}{l}\text { S.19 Frequent } \\
\text { periods while } \\
\text { applications are } \\
\text { unavailable }\end{array}$ & $\begin{array}{l}\text { AF.18 Application and } \\
\text { User Location Diagram } \\
\text { AF.25 Processing Diagram }\end{array}$ & $\begin{array}{l}\text { A.07 Enterprise coherence } \\
\text { assessment }\end{array}$ \\
\hline & $\begin{array}{l}\text { S.20 Information } \\
\text { consistency or } \\
\text { integrity problems }\end{array}$ & $\begin{array}{l}\text { AF.12 Data Entity/Data } \\
\text { Component Catalogue } \\
\text { AF.13 Data Entity/ } \\
\text { Business Function Matrix }\end{array}$ & $\begin{array}{l}\text { A.07 Enterprise coherence } \\
\text { assessment }\end{array}$ \\
\hline & $\begin{array}{l}\text { S.21 Undefined } \\
\text { business service } \\
\text { levels }\end{array}$ & $\begin{array}{l}\text { AF.04 Contract/Measure } \\
\text { Catalogue }\end{array}$ & A.03 Coverage analysis \\
\hline
\end{tabular}




\section{Case Study}

To demonstrate the applicability of the proposed framework, as well as to better understand how the proposed framework works in practice, a case study has been conducted. The case study clarifies the operation of the framework by applying it in the context of a real EA model structure. The empirical investigation focuses on a road management authority. The study was carried out in fragment of the road management authority's EA model structure. It describes a fleet management initiative, showing the relevant EA models and artifacts to be modified during the progression of the project. Figure 3 shows EA model contents investigated in this project. The model structure consists of 4 EA domains: Business Architecture, Data Architecture, Application Architecture and Technology Architecture. These domains are connected to the corresponding TOGAF ADM phases [21]. EA domains contain several artifacts, indicated as rectangles in the figure. Artifacts are connected with each other according to the possible relationships in content between EA models/artifacts.

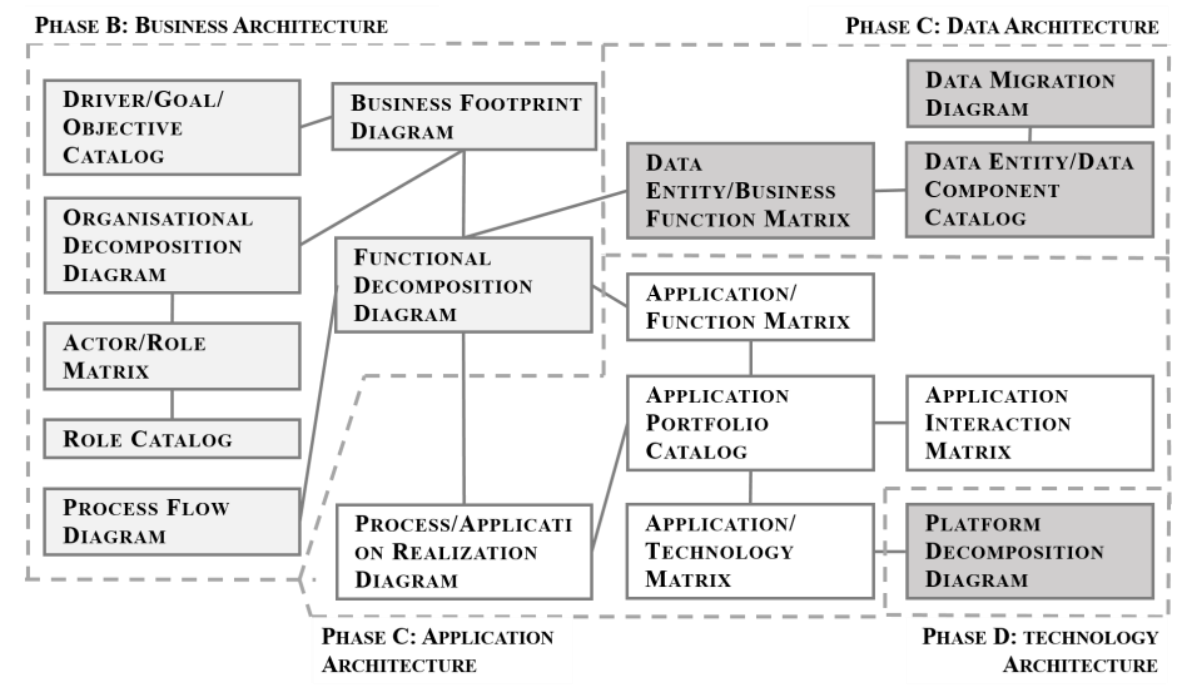

Fig. 3. EA model structure at the road management authority

To highlight the feasibility of the proposed framework, Table 9 shows an excerpt from the results of dependency analysis between business process tasks and applications. In this illustrative example the business processes of Road Control and Dispatcher Service are matched with application components that play essential role in business process realization. The result of the dependency analysis appears in a matrix form. Rows represent business process tasks, while applications are illustrated in columns. Dependency relations are displayed in cells: business process task depends on an application during the sequence flow of the business process. 
Table 9. Excerpt from a dependency analysis between business process tasks and applications

\begin{tabular}{|c|c|c|c|c|c|c|c|}
\hline APPLICATION & & & & & & & \\
\hline BUSINESS PROCESS TASK & 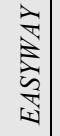 & $\begin{array}{l}\vdots \\
\vdots \\
\vdots \\
\vdots \\
\vdots \\
\vdots\end{array}$ & 胥 & $\underset{\downarrow}{\lessgtr}$ & 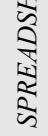 & 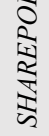 & 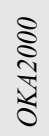 \\
\hline Administrating road control tasks & & & $\bullet$ & & $\bullet$ & & \\
\hline Forwarding information & $\bullet$ & $\bullet$ & & & & & \\
\hline Information recording and consolidation & & & & $\bullet$ & & & \\
\hline Receiving notification & & & & & & - & \\
\hline Road control plan preparation & & & & & $\bullet$ & $\bullet$ & $\bullet$ \\
\hline Road control plan verification & & & & & - & & \\
\hline
\end{tabular}

The example illustrates misalignment symptom S.07 Business process task supported by more than one application, which is a typical symptom of P.01 Strategy Execution perspective, C.02 Matching of Business Structure and IT Structure domains perspective component. The artifact that may contain this symptom is $A F .16$ Application/ Function Matrix. Suitable analysis that is able to detect the symptom in the artifact is A.01 Dependency analysis. As we can see from the figure, three business process tasks fulfil the requirements of this misalignment symptom: Administrating road control tasks, Forwarding information and Road control plan preparation.

Another symptom that can be verified by matching business process tasks and applications is S.06 Application functionality does not support at least one business process task. It is also a typical symptom of P.01 Strategy Execution perspective, C.02 Matching of Business Structure and IT Structure domains perspective component. The artifact that may contain this symptom is also AF.16 Application/ Function Matrix. Finally, suitable analysis that is able to detect the symptom in the artifact is also A.01 Dependency analysis. Contrary to the similarities in misalignment symptom set up, the above introduced excerpt does not show the realization of this symptom. As we can see from this fragment of dependency analysis, each application plays role in the realization of the illustrated business process tasks.

\section{Related Work}

There have been many attempts to investigate reciprocal contributions between strategic (mis)alignment assessment and EA analysis. Recently, there has been an increased interest in EA-based alignment assessment, especially in matching EA domains to evaluate the state of alignment in an organization. The following section provides an insight into the components of this concept: 1) EA analysis 2) misalignment assessment and 3) enterprise architecture alignment. 
A number of research efforts have focused on proposing models for EA analysis EA-based analysis types that are capable of assessing EA models. [5] and [22] introduce general process models for EA analysis. [5], [13] and [14] propose potential EA analysis categorizations according to e.g. 1) quantitative / qualitative, or 2) static / dynamic groupings. [3], [14] and [23] propose EA analysis collections. Tools for supporting the process of EA analysis are expounded by [4] and [5]. Several works have addressed the problem of EA analysis. All these works explore the applicability of EA analysis for EA evaluation, however, they do not specialize EA analysis for (mis)alignment assessment.

In the literature, different misalignment assessment techniques have been put forward to succeed in dealing with alignment evaluation from misalignment perspective. Most of them are symptom-based [6], [19], while other works such as [16] focused on proposing a process for misalignment assessment. Several approaches have been developed, but they do not provide any support for EA-based implementation.

The problem of enterprise architecture alignment has been extensively studied in the literature. [1] focuses on the integration of business and IT architecture domains. It collects requirements for architecture alignment and propose artifacts for alignment architecture. [7] deals with semi-automatic business process and data architecture alignment. It detects alignment patterns in the EA domains. [9] proposes an approach which supports architecture alignment. [17] introduces an EA metamodel for different business-IT alignment situations. [24] provides a description about an ideal alignment situation. EA alignment methods try to integrate alignment evaluation frameworks, misalignment assessment frameworks and EA analysis techniques to propose EAbased tools for (mis)alignment assessment. However, for the most part, existing approaches have no explicit potential for misalignment symptom detection. None of the proposed techniques can be directly applied to this problem.

The contribution of this study extends results on approaching EA-based misalignment symptom detection. The framework proposed in this paper can be considered as a precursory step for integrating the concepts and potentials of EA analysis, (mis)alignment assessment and EA alignment. In this framework typical misalignment symptoms are connected with relevant EA artifacts and suitable EA analysis types along the traditional alignment perspectives.

\section{Conclusion and Future Work}

In this paper a new way of misalignment symptom detection have been presented, which is able to reveal typical symptoms along the four traditional alignment perspectives by assessing the underlying EA models. The proposed artifact-based misalignment detection framework is built on matching the symptoms of misalignment with possible containing artifacts and suitable EA analysis types along alignment perspectives. The proposed framework has the potential to extend our understanding on assessing the state of misalignment in a complex EA model structure. The framework allowed us to identify and detect malfunctioning procedures along the alignment perspectives. It highlighted the importance of and a need for both 
an artifact-based and an EA analysis-based approach. The main contribution of the paper was that it connected typical misalignment symptoms to relevant containing artifacts and suitable EA analysis types along the perspectives of the SAM model.

The construction and operation of the framework have been discussed and explained in detail in the previous sections. To illustrate the feasibility of the proposed framework in practice as well as to provide guidance on applicability, a case study was performed. Examples of mismatches have been provided in the investigated EA models by using the proposed artifact-based and EA analysis-based approach. With this case study considerable progress has been made with regard to the practical application of the proposed framework. However, this study also encounters some challenges and questions in need of further investigations. Topics reserved for further examinations include 1) the automatization of EA analysis types and 2) decoupling the framework from built-in EA tool features. The next research step will be to focus on a tool-independent, automated implementation of the artifact-based misalignment symptom detection framework. In the meantime, a general assessment framework will be developed on alignment performance to be able to give feedback after detecting misalignment symptoms in the investigated companies. Feedback will include both alignment performance evaluation and possible misalignment correction and realignment activities. Apart from automating the framework, there are also some less radical development initiatives. As part of future work, the approach will be evaluated against some set of testable criteria. Future work will also concentrate on further refinements on the proposed framework: to enhance the accuracy and quality of misalignment symptom detection. Additionally, even more discussion is planned to provide on its practical applicability. Finally, since results are promising, the framework should be validated on some more complex EA model environments within other organizations.

\section{References}

1. Aier, S., Winter, R.: Virtual Decoupling for IT/Business Alignment - Conceptual Foundations, Architecture Design and Implementation Example. Business \& Information Systems Engineering 2009(2), 150-163 (2009)

2. Baets, W.: Aligning Information Systems with Business Strategy. Journal of Strategic Information Systems 1(4), 205-213 (1992)

3. Buckl, S., Matthes, F., Schweda, C.M.: Classifying Enterprise Architecture Analysis Approaches. In: Poler, R., van Sinderen, M., Sanchis, R. (eds.) IWEI 2009. LNBIP, vol. 38, pp. 66-79. Springer, Heidelberg (2009)

4. Buckl, S., Buschle, M., Johnson, P.: A Meta-language for Enterprise Architecture Analysis. In: Halpin, T., Nurcan, S., Krogstie, J., Soffer, P., Proper, E., Schmidt, R., Bider, I. (eds.) CAiSE 2011 (BPMDS 2011 - EMMSAD, 2011). LNBIP, vol. 81, pp. 511-525. Springer, Berlin (2011)

5. Buschle, M., Ullberg, J., Franke, U., Lagerström, R., Sommestad, T.: A Tool for Enterprise Architecture Analysis Using the PRM Formalism. In: Soffer, S., Proper, E. (eds.) CAiSE Forum 2010. LNBIP, vol. 72, pp. 108-121. Springer, Berlin (2011)

6. Carvalho, G., Sousa, P.: Business and Information Systems MisAlignment Model (BISMAM): An Holistic Model leveraged on Misalignment and Medical Sciences Approaches. In: Johannesson, P., Gordijn, J. (eds.) Proceedings of the Third International 
Workshop on Business/IT Alignment and Interoperability (BUSITAL'08). CEUR, vol. 336, pp. 104-119. CEUR-WS, Aachen (2008)

7. Castellanos, C., Correal, D.: KALCAS: A FrameworK for Semi-automatic ALignment of Data and Business ProCesses ArchitectureS. In: Morzy, T., Haerder, T., Wrembel, R. (eds.) ADBIS 2012. LNCS, vol. 7503, pp. 111-124. Springer, Heidelberg (2012)

8. Chan, Y.E., Reich, B.H.: IT alignment: what have we learned? Journal of Information Technology 22 (2007), 297-315 (2007)

9. Clark, T., Barn, B.S., Oussena, S.: A Method for Enterprise Architecture Alignment. In: Proper, E., Gaaloul, K., Harmsen, F., Wrycza, S. (eds.) PRET 2012. LNBIP, vol. 120, pp. 48-76. Springer, Heidelberg (2012)

10. Coleman, P., Papp, R.: Strategic Alignment: Analysis of Perspectives. In: Murray, M., Weistroffer, H.R. (eds.) Proceedings of the 2006 Southern Association for Information Systems Conference, pp. 242-250. MPublishing, Michigan (2006)

11. DoDAF Architecture Framework, http://dodcio.defense.gov/Portals/0/ Documents/DODAF/DoDAF v2-02 web.pdf

12. Henderson, J.C., Venkatraman, N.: Strategic Alignment: Leveraging information technology for transforming organizations. IBM Systems Journal 32(1) 4-16 (1993)

13. Lankhorst, M.:Enterprise Architecture at Work. Modelling, Communication and Analysis. Springer, Heidelberg (2013)

14. Niemann, K.D.: From Enterprise Architecture to IT Governance. Elements of Effective IT Management. Friedr. Vieweg \& Sohn Verlag, Wiesbaden (2006)

15. Noran, O.: A Decision Support Framework for Collaborative Networks. International Journal of Production Research 47(17) 4813-4832 (2009)

16. Pereira, C.M., Sousa, P.: Enterprise Architecture: Business and IT Alignment. In: ACM Symposium on Applied Computing, pp. 1344-1345. ACM, New York (2005)

17. Saat, J., Franke, U., Lagerström, R., Ekstedt, M.: Enterprise Architecture Meta Models for IT/Business Alignment Situations. In: 14th IEEE International Enterprise Distributed Object Computing Conference, pp. 14-23. IEEE Press, New York (2010)

18. Scott Morton, M.S.: The Corporation of the 1990s: Information technology and organizational transformation. Oxford Press, London (1991)

19. Sousa, P., Pereira, C.M., Marques, J.A.: Enterprise Architecture Alignment Heuristics. Microsoft Architects Journal 4, 34-39 (2005)

20. Strong, D.M., Volkoff, O.: Understanding Organization-Enterprise System Fit: A Path to Theorizing the Information Technology Artifact. MIS Quarterly 34(4), 731-756 (2010)

21. The Open Group Architecture Framework (TOGAF), http: / theopengroup .org/

22. Ullberg, J., Franke, U., Buschle, M., Johnson, P.: A Tool for Interoperability Analysis of Enterprise Architecture Models using Pi-OCL. In: Popplewell, K., Harding, J., Poler, R., Chalmeta, R. (eds.) Enterprise Interoperability IV. Making the Internet of the Future for the Future of Enterprises, pp. 81-90. Springer, London (2010)

23. Wagter, R., Proper, H.A., Witte, D.: A Practice-Based Framework for Enterprise Coherence. In: Proper, E., Gaaloul, K., Harmsen, F., Wrycza, S. (eds.) PRET 2012. LNBIP, vol. 120, pp. 77-95. Springer, Heidelberg (2012)

24. Wegmann, A., Regev, G., Rychkova, I., Lam-Son Le, de la Cruz, J.D., Julia, P.: Business and IT Alignment with SEAM for Enterprise Architecture. In: 11th IEEE International Enterprise Distributed Object Computing Conference, pp. 111-121. IEEE Press, New York (2007)

25. Zachman, J.A.: A Framework for Information Systems Architecture. IBM Systems Journal 26(3), 276-292 (1987) 